\title{
The Effect of Nitrous Oxide on the Intraocular Pressure in Patients Undergoing Abdominal Surgery under Sevoflurane and Remifentanil Anesthesia
}

\author{
Toru Goyagi*, Takehito Sato, Takashi Horiguchi, Toshiaki Nishikawa \\ Department of Anesthesia and Intensive Care Medicine, Akita University Graduate \\ School of Medicine, Akita, Japan \\ Email: "tgoyagi@doc.med.akita-u.ac.jp
}

Received 19 May 2016; accepted 6 June 2016; published 9 June 2016

Copyright (C) 2016 by authors and Scientific Research Publishing Inc.

This work is licensed under the Creative Commons Attribution International License (CC BY). http://creativecommons.org/licenses/by/4.0/

(c) (i) Open Access

\begin{abstract}
Introduction: Although inhalational anesthesia and nitrousoxide $\left(\mathrm{N}_{2} \mathrm{O}\right)$ are known to affect the intraocular pressure (IOP), little is known about the effect of nitrousoxide on the IOP during sevoflurane and remifentanil anesthesia. In the present study, we examined the effect of balanced anesthesia on the IOP. Materials and Methods: After obtaining informed consent, the patients undergoing abdominal surgery under general anesthesia were divided into two groups: $\mathrm{N}_{2} \mathrm{O}$ group (n $=10)$ and control group $(n=12)$. General anesthesia was maintained with remifentanil $(0.05-0.3$ $\mu \mathrm{g} / \mathrm{kg} / \mathrm{min}$ ), $33 \% \mathrm{O}_{2}$ and $1.2 \%$ sevoflurane to keep $\mathrm{ETCO}_{2}$ of $35-40 \mathrm{mmHg}$ following tracheal intubation. After baseline measurement of IOP (TO, 20 minutes after injection of anesthesia), the patients in the $\mathrm{N}_{2} \mathrm{O}$ group received $67 \%$ nitrousoxide, and the patients in the control group received air, with $\mathrm{O}_{2}$ and $1.2 \%$ sevoflurane. Then, IOP was measured at 1 hour (T1), 2 hours (T2), and 3 hours (T3) after anesthesia induction in the supineposition. Blood pressure and heart rate were recorded at the same time interval. Results: There was no significant difference in the IOP at any period between the two groups. In both groups, the IOP at the T3 was significantly higher than that at T0. Conclusion: These results suggest that $\mathrm{N}_{2} \mathrm{O}$ does not affect the IOP in patients undergoing abdominal surgery under sevoflurane and remifentanil anesthesia.
\end{abstract}

Keywords

Intraocular Pressure, Nitrous Oxide, Balanced Anesthesia

\footnotetext{
${ }^{*}$ Corresponding author.
}

How to cite this paper: Goyagi, T., Sato, T., Horiguchi, T. and Nishikawa, T. (2016) The Effect of Nitrous Oxide on the Intraocular Pressure in Patients Undergoing Abdominal Surgery under Sevoflurane and Remifentanil Anesthesia. Open Journal of Anesthesiology, 6, 85-90. http://dx.doi.org/10.4236/ojanes.2016.66014 


\section{Introduction}

Intraocular pressure (IOP) is known to change during perioperative period due to inhalational anesthetic agents like halothane, isoflurane and sevoflurane [1] [2], and opioids such as fentanyl, alfentanil and remifentanil [3]-[7]. Schäfer et al. have shown that IOP more reduces during anesthesia with propofol than with sevoflurane, both combined with remifentanil [8].

Although nitrous oxide $\left(\mathrm{N}_{2} \mathrm{O}\right)$ may affect IOP [9]-[12], one report indicates that IOP with desflurane and $\mathrm{N}_{2} \mathrm{O}$ does not differ compared with desflurane alone in dogs [11]. Moreover, $\mathrm{N}_{2} \mathrm{O}$ has been shown to have no influence in healthy volunteer [13]. On the other hand, detrimental effect of $\mathrm{N}_{2} \mathrm{O}$ is reported, indicated that the use of $\mathrm{N}_{2} \mathrm{O}$ in patients, who undergo vitreoretinal procedures cause retinal or optic nerve ischemia, results in visual loss [14]-[16].

Sevoflurane combined with remifentanil anesthesia is not known to influence IOP. In addition, it is not well known about the effect of $\mathrm{N}_{2} \mathrm{O}$ on IOP in patients receiving sevoflurane and remifentanil anesthesia in patients with abdominal surgery. Therefore, we examine the effect of $\mathrm{N}_{2} \mathrm{O}$ on the IOP in patients undergoing abdominal surgery under sevoflurane and remifentanil anesthesia.

\section{Materials and Methods}

The study was approved by the Ethics Committee of Akita University Hospital and registered with the UMIN clinical trials registry (ID: UMIN000020241). After obtained informed consent, 22 ASA physical status I or II patients scheduled for elective abdominal surgery were studied. We excluded patients with allergies, unstable angina, congestive heart failure, glaucoma and other ophthalmic disease and past history of eye surgery. The patients were allocated to either of two groups; $\mathrm{N}_{2} \mathrm{O}$ group $(\mathrm{n}=10)$ and control group $(\mathrm{n}=12)$. All patients were premeditated with ranitidine150 mg 90 min before general anesthesia. Anesthesia was induced with propofol 1 $\mathrm{mg} / \mathrm{kg}$, continuous infusion of remifentanil and rocronium $1 \mathrm{mg} / \mathrm{kg}$. The trachea was intubated, and lung ventilation was adjusted to maintain end-tidal $\mathrm{CO}_{2}$ at $35-40 \mathrm{mmHg}$ with $33 \%$ oxygen, $1.2 \%$ sevoflurane and remifentanil $(0.05-0.3 \mu \mathrm{g} / \mathrm{kg} / \mathrm{min})$. The patients in the $\mathrm{N}_{2} \mathrm{O}$ group received $33 \%$ oxygen and $67 \% \mathrm{~N}_{2} \mathrm{O}$, and the patients in the control group received air instead of oxygen and $\mathrm{N}_{2} \mathrm{O}$. IOP was measured at 20 min after induction of anesthesia (T0), 1 hour after T0 (T1), 2 hours after T0 (T2), and 3 hours after T0 (T3) at the supine position using PT100 portable non-contact tonometer (Reichert, INC, Depew, NY, USA). Blood pressure and heart rate were recorded at the same time interval. We measured the IOP three times in each epoch, and then calculated the mean value.

We defined hypotension as a SBP (systolic blood pressure) $\leq 80 \%$ of the preinduction baseline SBP, hypertension as a SBP $>140 \%$ of the preinduction baseline SBP, and bradycardia as HR $<40 \mathrm{bpm}$. Hypotension was treated with an intravenous bolus of phenylephrine $50 \mu \mathrm{g}$ or ephedrine $5 \mathrm{mg}$ and bradycardia was treated with an intravenous bolus of atropine $0.5 \mathrm{mg}$.

Data were expressed as mean \pm SD. Student t-test was used to compare the data between two groups, and analysis of variance for repeated measures was performed to access differences within the groups. $P<0.05$ was considered as statistically significant.

\section{Results}

The patients in the two groups were comparable with regards to demographic and hemodynamic data (Table 1 and Table 2).

Although there were no significant differences between the two groups in IOP at any measuring points, IOP at $\mathrm{T} 3$ was significantly higher than that at $\mathrm{T} 0$ in both groups (Figure 1).

Table 1. Patients’ demographic data.

\begin{tabular}{cccc}
\hline & $\mathrm{N}_{2} \mathrm{O}$ group & Control group & $P$ value \\
\hline Age (years) & $59 \pm 12$ & $55 \pm 15$ & 0.64 \\
Gender (male/femal) & $4 / 6$ & $3 / 9$ & 0.65 \\
Height (cm) & $157 \pm 13$ & $159 \pm 12$ & 0.63 \\
Weight (kg) & $56 \pm 14$ & $58 \pm 12$ & 0.65 \\
ASA (grade1/2) & $4 / 6$ & $3 / 9$ & 0.65 \\
\hline
\end{tabular}

Values are mean \pm SD or numbers. No significant difference. 


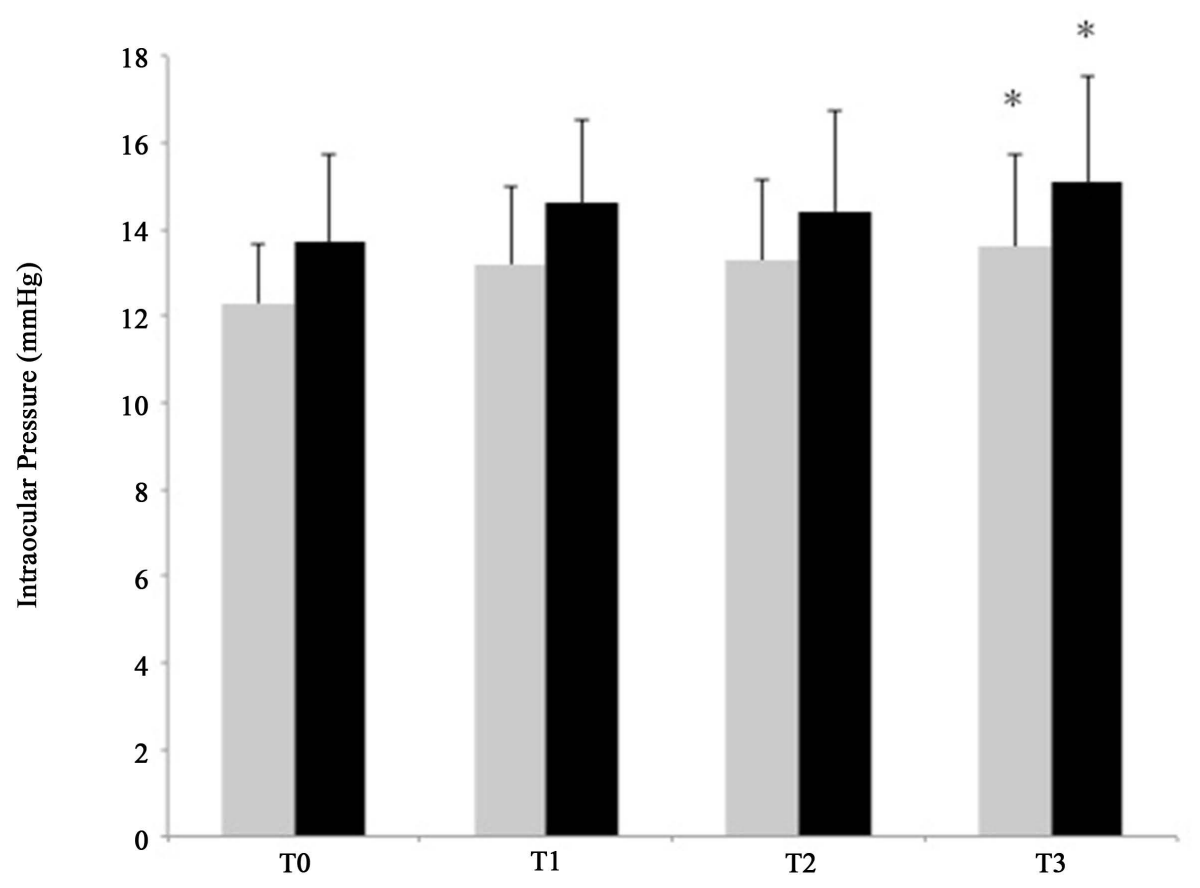

Figure 1. Changes of the intraocular pressure (IOP) during study period. IOP did not differ between the $\mathrm{N}_{2} \mathrm{O}$ groups (gray bar) and the control group (black bar) at any measuring points. IOP values at T3 in both groups were higher than those at T0. $\mathrm{T} 0=20$ min after induction of anesthesia, T1 = 1 hour after T0, T2 = 2 hours after T0, T3 = 3 hours after T0. Values were mean \pm SD. ${ }^{*} P<0.05$ versus T0.

Table 2. Changes of intraocular pressure.

\begin{tabular}{|c|c|c|c|c|c|c|}
\hline & Group & T0 & $\mathrm{T} 1$ & $\mathrm{~T} 2$ & T3 & $P$ value \\
\hline \multirow{2}{*}{$\begin{array}{c}\text { Mean Blood Pressure } \\
\text { (mmHg) }\end{array}$} & $\mathrm{N}_{2} \mathrm{O}$ group & $69 \pm 11$ & $68 \pm 9$ & $68 \pm 8$ & $69 \pm 10$ & \multirow{2}{*}{0.84} \\
\hline & Control group & $70 \pm 14$ & $73 \pm 10$ & $67 \pm 7$ & $72 \pm 11$ & \\
\hline \multirow{2}{*}{$\begin{array}{l}\text { Heart Rate } \\
\text { (beats/min) }\end{array}$} & $\mathrm{N}_{2} \mathrm{O}$ group & $71 \pm 8$ & $69 \pm 10$ & $68 \pm 13$ & $69 \pm 11$ & \multirow{2}{*}{0.09} \\
\hline & Control group & $64 \pm 11$ & $63 \pm 12$ & $62 \pm 10$ & $67 \pm 9$ & \\
\hline \multirow{2}{*}{$\mathrm{ETCO}_{2}(\mathrm{mmHg})$} & $\mathrm{N}_{2} \mathrm{O}$ group & $36 \pm 0.8$ & $36 \pm 0.9$ & $36 \pm 0.8$ & $37 \pm 1.4$ & \multirow{2}{*}{0.13} \\
\hline & Control group & $35 \pm 0.4$ & $36 \pm 0.9$ & $36 \pm 0.9$ & $36 \pm 1.2$ & \\
\hline
\end{tabular}

$\mathrm{T} 0=20$ minutes after induction, $\mathrm{T} 1=1$ hour after $\mathrm{T} 0, \mathrm{~T} 2=2$ hour after $\mathrm{T} 0, \mathrm{~T} 3=3$ hour after T0. Values $=$ mean $\pm \mathrm{SD}$. There were no significant different between two groups.

There was no patient who developed hypertension, hypotension and bradycardia during the study period.

\section{Discussion}

We conducted a prospective, randomized study to evaluate the effects of $\mathrm{N}_{2} \mathrm{O}$ on IOP during sevoflurane and remifentanil anesthesia. Our results demonstrated that $\mathrm{N}_{2} \mathrm{O}$ did not affect IOP during 3 hours in patients under general anesthesia with sevoflurane and remifentanil. However, IOP increased at 3 hours after induction of anesthesia compared with starting point in both patients with and without $\mathrm{N}_{2} \mathrm{O}$.

Intraocular pressure (IOP) is known to changing at perioperative period due to anesthetic maneuvers [3] [17], anesthetic agents [4] [18]-[21], and patient's position [22]-[27] and hemodynamics [28]. Tracheal intubation [29], succinylcholine [5]-[7], inhalational anesthesia [1] [2] [8], and nitrous oxide $\left(\mathrm{N}_{2} \mathrm{O}\right)$ [21] may influence IOP. Inhalational anesthetics and propofol have been shown to decrease IOP [8], whereas succinylcholine can increase IOP [5]-[7]. Previous studies demonstrated that general anesthesia with halothane, enflurane, propofol, 
and fentanyl would decrease IOP after tracheal intubation [2]-[5]. These range of reduction varied with type of anesthesia. Tracheal intubation could lead to elevate IOP [17], however, this effect can be minimized by various method [5]-[7]. In this study, we did not measure IOP before anesthesia. Therefore, we could not compare the IOP values between before and after tracheal intubation. Moreover, none of the previous reports that showing the changes of the IOP during sevoflurane and remifentanil anesthesia in patients undergoing abdominal surgery was existed.

Although major determinants for IOP include the production rate of aqueous humor, vitreous volume, sclera rigidity, choroidal blood volume, and orbicularis oculi muscle tension [12], there have been few studies to assess the effect of nitrous oxide on IOP [10]-[13]. Lalwani et al. have shown that nitrous oxide inhalation did not significantly change IOP from baseline values in a population of healthy adults [13]. Our result of present study was consistent with their result.

IOP at T3 in both groups were significant greater than IOP at T0 in this study. Because hemodynamics and anesthesia was similar during the study period, the possibility of blood pressure and anesthesia can be excluded. However, it remains unknown what was the effect of IOP at T3. IOP at T3 in both group were within normal range and did not differ between the two groups. Therefore, it is clear that $\mathrm{N}_{2} \mathrm{O}$ does not affect the elevation of IOP at T3.

Based on the present and previous similar study [11]-[13], the effect of $\mathrm{N}_{2} \mathrm{O}$ would not affect the IOP during 3 hours sevoflurane and remifentanil anesthesia in patients undergoing abdominal surgery. Our study had the following possible limitations. We had recruited the small number of patients with ASA physical status I or II. It remains unknown if the results will be applicable to other populations such as patients with glaucoma, under head down position surgery or laparoscopy. The difference of the IOP before and after sevoflurane and remifentanil anesthesia was not clear from this study and warranted the additional studies. Future studies will be needed to clarify the effects of $\mathrm{N}_{2} \mathrm{O}$ long exposure on IOP in other patient populations and surgery.

\section{Conclusion}

In conclusion, $\mathrm{N}_{2} \mathrm{O}$ did not affect IOP during abdominal surgery under sevoflurane and remifentanil anesthesia. With or without $\mathrm{N}_{2} \mathrm{O}$, IOP at 3 hours after induction of anesthesia was significantly higher than that at 20 minutes after (T0).

\section{Acknowledgements}

No one other than the authors contributed substantially to the performance of this study or to the drafting of the manuscript.

\section{Competing Interest}

The authors have no conflicts of interest to declare, financial or otherwise.

\section{References}

[1] Mirakhur, P.K., Elliott, P., Shepherd, W.F. and McGalliard, J.N. (1990) Comparison of the Effects of Isoflurane and Halothane on Intraocular Pressure. Acta Anaesthesiologica Scandinavica, 34, 282-285. http://dx.doi.org/10.1111/j.1399-6576.1990.tb03086.x

[2] Runciman, J.C., Bowen-Wright, R.M., Welsh, N.H. and Downing, J.W. (1978) Intra-Ocular Pressure Changes during Halothane and Enflurance Anaesthesia. British Journal of Anaesthesia, 50, 371-374. http://dx.doi.org/10.1093/bja/50.4.371

[3] Sator-Katzenschlager, S.M., Oehmke, M.J., Deusch, E., Dolezal, S., Heinze, G. and Wedrich, A. (2004) Effects of Remifentanil and Fentanyl on Intraocular Pressure during the Maintenance and Recovery of Anaesthesia in Patients Undergoing Non-Ophthalmic Surgery. European Journal of Anaesthesiology, 21, 95-100. http://dx.doi.org/10.1097/00003643-200402000-00003

[4] Feneck, R.O. and Durkin, M.A. (1987) A Comparison between the Effects of Fentanyl, Droperidol with Fentanyl, and Halothane Anaesthesia on Intra-Ocular Pressure in Adults. Anaesthesia, 42, 266-269. http://dx.doi.org/10.1111/j.1365-2044.1987.tb03037.x

[5] Zimmerman, A.A., Funk, K.J. and Tidwell, J.L. (1996) Propofol and Alfentanil Prevent the Increase in Intraocular Pressure Caused by Succinylcholine and Endotracheal Intubation during a Rapid Sequence Induction of Anesthesia. 
Anesthesia \& Analgesia, 83, 814-817.

[6] Ng, H.P., Chen, F.G., Yeong, S.M., Wong, E. and Chew, P. (2000) Effect of Remifentanil Compared with Fentanyl on Intraocular Pressure after Succinylcholine and Tracheal Intubation. British Journal of Anaesthesia, 85, 785-787. http://dx.doi.org/10.1093/bja/85.5.785

[7] Eti, Z., Yayci, A., Umuroglu, T., Gögüş, F.Y. and Bozkurt, N. (2000) The Effect of Propofol and Alfentanil on the Increase in Intraocular Pressure Due to Succinylcholine and Intubation. European Journal of Ophthalmology, 10, 105109.

[8] Schäfer, R., Klett, J., Auffarth, G., Polarz, H., Völcker, H.E., Martin, E. and Böttiger, B.W. (2002) Intraocular Pressure More Reduced during Anesthesia with Propofol than with Sevoflurane: Both Combined with Remifentanil. Acta Anaesthesiologica Scandinavica, 46, 703-706. http://dx.doi.org/10.1034/j.1399-6576.2002.460612.x

[9] al-Abrak, M.H. and Samuel, J.R. (1974) Further Observations on the Effects of General Anaesthesia on Intraocular Pressure in Man: Halothane in Nitrous oxide and Oxygen. British Journal of Anaesthesia, 46, 756-759. http://dx.doi.org/10.1093/bja/46.10.756

[10] Duncalf, D. and Foldes, F.F. (1973) Effect of Anesthetic Drugs and Muscle Relaxants on Intraocular Pressure. International Ophthalmology Clinics, 13, 21-33. http://dx.doi.org/10.1097/00004397-197301320-00004

[11] Almeida, D.E., Nishimori, C.T., Oria, A.P., Paula, D.P., Nunes, N. and Laus, J.L. (2008) Effects of Nitrous Oxide on IOP and Pupillary Diameter in Dogs Anesthetized with Varying Concentrations of Desflurane. Veterinary Ophthalmology, 11, 170-176. http://dx.doi.org/10.1111/j.1463-5224.2008.00616.X

[12] Artru, A.A. and Momota, Y. (1999) Trabecular Outflow Facility and Formation Rate of Aqueous Humor during Anesthesia with Sevoflurane-Nitrous Oxide or Sevoflurane-Remifentanil in Rabbits. Anesthesia \& Analgesia, 88, 781-786.

[13] Lalwani, K., Fox, E.B., Fu, R., Edmunds, B. and Kelly, L.D. (2012) The Effect of Nitrous Oxide on Intra-Ocular Pressure in Healthy Adults. Anaesthesia, 67, 256-260. http://dx.doi.org/10.1111/j.1365-2044.2011.06989.x

[14] Lockwood, A.J. and Yang, Y.F. (2008) Nitrous Oxide Inhalation Anaesthesia in the Presence of Intraocular Gas Can Cause Irreversible Blindness. British Dental Journal, 204, 247-248. http://dx.doi.org/10.1038/bdj.2008.158

[15] Vote, B.J., Hart, R.H., Worsley, D.R., Borthwick, J.H., Laurent, S. and McGeorge, A.J. (2002) Visual Loss after Use of Nitrous Oxide Gas with General Anesthetic in Patients with Intraocular Gas Still Persistent up to 30 Days after Vitrectomy. Anesthesiology, 97, 1305-1308. http://dx.doi.org/10.1097/00000542-200211000-00038

[16] Lee, E.J. (2004) Use of Nitrous Oxide Causing Severe Visual Loss 37 Days after Retinal Surgery. British Journal of Anaesthesia, 93, 464-466. http://dx.doi.org/10.1093/bja/aeh213

[17] Watts, P., Lim, M.K., Gandhewar, R., Mukherjee, A., Wintle, R., Armstrong, T., Zatman, T., Jones, R. and Al Madfai, H. (2007) The Effect of Laryngeal Mask Airway Insertion on Intraocular Pressure Measurement in Children Receiving General Anesthesia. American Journal of Ophthalmology, 144, 507-510.e1. http://dx.doi.org/10.1016/j.ajo.2007.06.010

[18] Nagdeve, N.G., Yaddanapudi, S. and Pandav, S.S. (2006) The Effect of Different Doses of Ketamine on Intraocular Pressure in Anesthetized Children. Journal of Pediatric Ophthalmology \& Strabismus, 43, 219-223.

[19] Warner, L.O., Bremer, D.L., Davidson, P.J., Rogers, G.L. and Beach, T.P. (1989) Effects of Lidocaine, Succinylcholine, and Tracheal Intubation on Intraocular Pressure in Children Anesthetized with Halothane-Nitrous Oxide. Anesthesia \& Analgesia, 69, 687-690. http://dx.doi.org/10.1213/00000539-198911000-00027

[20] Guedes, Y., Rakotoseheno, J.C., Leveque, M., Mimouni, F. and Egreteau, J.P. (1988) Changes in Intra-Ocular Pressure in the Elderly during Anaesthesia with Propofol. Anaesthesia, 43, 58-60. http://dx.doi.org/10.1111/j.1365-2044.1988.tb09072.x

[21] Dear, G.D., Hammerton, M., Hatch, D.J. and Taylor, D. (1987) Anaesthesia and Intra-Ocular Pressure in Young Children. A Study of Three Different Techniques of Anaesthesia. Anaesthesia, 42, 259-265. http://dx.doi.org/10.1111/j.1365-2044.1987.tb03036.x

[22] Thomson, M.F., Brock-Utne, J.G., Bean, P., Welsh, N. and Downing, J.W. (1982) Anaesthesia and Intra-Ocular Pressure: A Comparative of Total Intravenous Anaesthesia Using Etomidate with Conventional Inhalation Anaesthesia. Anaesthesia, 37, 758-761. http://dx.doi.org/10.1111/j.1365-2044.1982.tb01317.x

[23] Raz, O., Boesel, T.W., Arianayagam, M., Lau, H., Vass, J., Huynh, C.C., Graham, S.L. and Varol, C. (2015) The Effect of the Modified Z Trendelenburg Position on Intraocular Pressure during Robotic Assisted Laparoscopic Radical Prostatectomy: A Randomized, Controlled Study. The Journal of Urology, 193, 1213-1219.

[24] Cheng, M.A., Todorov, A., Tempelhoff, R., McHugh, T., Crowder, C.M. and Lauryssen, C. (2001) The Effect of Prone Positioning on Intraocular Pressure in Anesthetized Patients. Anesthesiology, 95, 1351-1355. http://dx.doi.org/10.1097/00000542-200112000-00012

[25] Sugata, A., Hayashi, H., Kawaguchi, M., Hasuwa, K., Nomura, Y. and Furuya, H. (2012) Changes in Intraocular Pressure during Prone Spine Surgery under Propofol and Sevoflurane Anesthesia. Journal of Neurosurgical Anesthesiology, 
24, 152-156. http://dx.doi.org/10.1097/ana.0b013e31823fe822

[26] Yoo, Y.C., Shin, S., Choi, E.K., Kim, C.Y., Choi, Y.D. and Bai, S.J. (2014) Increase in Intraocular Pressure Is Less with Propofol than with Sevoflurane during Laparoscopic Surgery in the Steep Trendelenburg Position. Canadian Journal of Anesthesia/Journal Canadien d'Anesthésie, 61, 322-329. http://dx.doi.org/10.1007/s12630-014-0112-2

[27] Hwang, J.W., Oh, A.Y., Hwang, D.W., Jeon, Y.T., Kim, Y.B. and Park, S.H. (2013) Does Intraocular Pressure Increase during Laparoscopic Surgeries? It Depends on Anesthetic Drugs and the Surgical Position. Surgical Laparoscopy, Endoscopy \& Percutaneous Techniques, 23, 229-232. http://dx.doi.org/10.1097/SLE.0b013e31828a0bba

[28] Buehner, E., Pietsch, U.C., Bringmann, A., Foja, C., Wiedemann, P. and Uhlmann, S. (2011) Effects of Propofol and Isoflurane Anesthesia on the Intraocular Pressure and Hemodynamics of Pigs. Ophthalmic Research, 45, 42-46. http://dx.doi.org/10.1159/000317060

[29] Bharti, N., Mohanty, B., Bithal, P.K., Dash, M. and Dash, H.H. (2008) Intra-Ocular Pressure Changes Associated with Intubation with the Intubating Laryngeal Mask Airway Compared with Conventional Laryngoscopy. Anaesthesia and Intensive Care, 36, 431-435. 